\title{
Cleveland Clinic Florida, Department of Colorectal Surgery announces the formation of the Alumni International Research Group
}

\author{
Steven D. Wexner
}

(C) Springer-Verlag 2009

The greatest strength of our department is the quality of the alumni we have trained. To date, over 500 individuals have participated in the research and clinical training programs at Cleveland Clinic Florida (Fig. 1). Because of the consistency of education of these individuals, and the unique facets of the camaraderie around the world, our alumni felt that continuing to work together would be of significant interest and major potential patient benefit. Therefore, our alumni have recently organized the Colorectal Alumni International Research (CAIR) group.

The CAIR group is a consortium by which research questions can be quickly answered by this homogeneously trained group of individuals. Ideas for trials will be reviewed by the Grant Committee and participation is eligible for all alumni of Cleveland Clinic Florida. I urge you to contact Dr. Lester Rosen and Dr. Christina Seo, the departmental representatives to the committee, to enroll. I look forward to all Cleveland Clinic Florida alumni actively participating in this new and exciting international cooperative endeavor.

Contact Information: Lester Rosen, MD

Email: rosenl@ccf.org

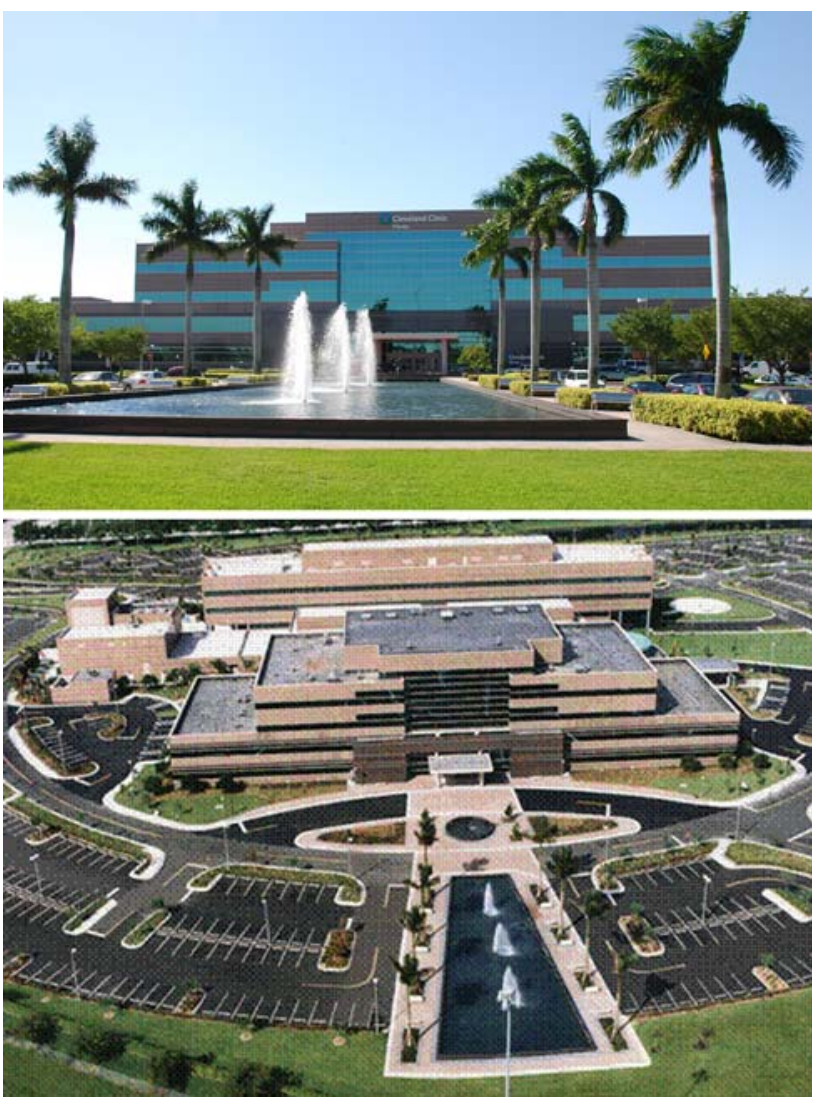

Fig. 1 Cleveland Clinic Florida (front). Photo courtesy of Badma Bashankaev, MD, Cleveland Clinic Florida
S. D. Wexner ( $\square)$

Department of Colorectal Surgery,

2950 Cleveland Clinic Blvd,

Weston, FL 33331, USA

e-mail: deanh@ccf.org 